\title{
State of the Art/Science: Visual Methods and Information Behavior Research
}

\author{
Jenna Hartel, PhD \\ Faculty of Information \\ University of Toronto, Canada \\ jenna.hartel@utoronto.ca
}

Anna Lundh, PhD

Swedish School of Library and Information Science

University of Boras, Sweden

anna.lundh@hb.se

\author{
Diane Sonnenwald, PhD \\ School of Library and Information Studies \\ University College, Dublin, Ireland \\ diane.sonnenwald@ucd.ie
}

\author{
Nancy Fried Foster, Phd \\ University of Rochester Libraries \\ University of Rochester, NY, USA \\ nancy.foster@rochester.edu
}

\begin{abstract}
This panel reports on methodological innovation now underway as information behavior scholars begin to experiment with visual methods. The session launches with a succinct introduction to visual methods by Jenna Hartel and then showcases three exemplar visual research designs. First, Dianne Sonnenwald presents the "information horizon interview" (1999, 2005), the singular visual method native to the information behavior community. Second, Anna Lundh (2010) describes her techniques for capturing and analyzing primary school children's information activities utilizing video recordings. Third, Nancy Fried Foster (Foster \& Gibbons, 2007) reports how students, staff and faculty members produce maps, drawings, and photographs as a means of contributing their specialist knowledge to the design of library technologies and spaces at the University of Rochester. Altogether, the panel will present a collage of innovative visual research designs and engage the associated epistemological, theoretical, methodological, and empirical issues. All speakers will have 15 minutes and be timed to allow a minimum of 30 minutes for audience questions, comments, and discussion. Upon the conclusion attendees will have gained: knowledge of the state of the art/science of visual methods in information behavior research; an appreciation for the richness the approach brings to the specialty; and a platform to take new visual research designs forward.
\end{abstract}

Keywords

information behavior, research methods, visual research,

\section{BACKGROUND}

Visual methods entail the use of images to learn about the social world. The predominant forms of data in social scientific research are words or numbers, yet data in visual forms can be an alternative or complementary medium of discovery. According to Weber (2008), images may prove valuable in research because they capture the ineffable; make us pay attention to things in a new way; and can be more accessible than most forms of academic discourse.
Through five modes images can facilitate inquiry: 1.) Images can be produced by participants as data, 2.) Found or existing images can be used as data or springboards for theorizing, 3.) Images and objects are useful to elicit or provoke other data, 4.) Images can be used for feedback and documentation of the research process, and 5.) Images are useful as a mode of interpretation and/or representation (Weber, 2008, p. 47).

\section{VISUAL METHODS AND INFORMATION BEHAVIOR RESEARCH}

In the information behavior specialty the first foray into visual methods was by Malone (1983), whose seminal research on office organization included photographs of office settings. Another early application was an exploratory study of librarian and student cyberexperiences; research subjects were asked to draw a concept map of the Internet (Scull, Milewski, \& Millen, 1999). The most significant innovation of a visual method for the study of information behavior was introduced in 2001: the information horizon interview (Sonnenwald, 1999, 2005), a technique in which subjects draw a map of their information horizon (an imagined landscape of information resources). In the neighboring research specialty of Computer Supported Collaborative Work, ethnomethodologically-informed ethnographers frequently employ video and photography to capture household information systems (Crabtree \& Rodden, 2004). Hartel conducted photographic inventories and produced sketches of culinary collections for her dissertation study of information phenomena in the hobby of gourmet cooking (2007; 2011). In her $\mathrm{PhD}$ research Lundh (2011; 2010; Lundh \& Alexandersson, 2012) included multimodal aspects of information activities by using a video camera when conducting studies of primary school pupils' information seeking and use. Our panel is the first public critique and discussion of this nascent methodological trend and aims to bring attention, momentum, and a narrative arc to this scattered history. 


\section{EPISTEMOLOGICAL AND COMPLEXITY}

The panel will broach the complex epistemological and methodological issues associated with visual research. Foremost, there is a tension between the potential objectivity or subjectivity of visual techniques and the resulting data. Images such as photographs and film appear to represent the world objectively and without interpretation. On the other hand, an image may be seen as socially and technically constructed, a "polysemic and ambiguous social and cultural artifact" (Wagner, 2001, p. 7). In this latter view, images are largely a reflection of visual culture and the way the researcher frames and then interprets the world. Following Prosser and Loxley (2008), the panel will demonstrate how each approach can play a legitimate and worthwhile role in information behavior research, and that many studies benefit from mixed-method designs.

\section{OPEN QUESTIONS IN VISUAL RESEARCH}

The panel will also engage important open questions underlying visual methods, such as: What qualifies as an image in visual research? Traditionally, visual methods imply photographs, while video, diagrams, and illustrations are also common. Arts-based research (Knowles \& Cole, 2008) employs formats such as cartoons and paintings among others, and multimedia further expands the visual possibilities. Another issue concerns the origin of the images during the research process. Visual data can be created by the researcher during data gathering or the research participant can be directed to visually represent his or her world. Similarly, images found in the field, or anywhere in culture, may also serve as data. Due to time restrictions, our panel cannot provide complete answers to these questions, but diverse viewpoints will be offered and an annotated bibliography will be given to attendees as a gateway to these debates.

\section{COMPOSITION OF THE PANEL}

The panel features an international line-up from four countries (Canada, Ireland, Sweden, USA). Each speaker will have 15 minutes. Their name, affiliation, presentation title, qualifications, and a sample of their visual data are provided below. Speakers will appear in the order listed.

\section{Dr. Jenna Hartel, "An Introduction to Visual Methods"}

Dr. Hartel conducts research on information behavior in serious leisure (Hartel, 2003, 2010) and she also studies and practices visual, ethnographic techniques. Inspired by the visual tradition in anthropology, she adapted the cultural inventory of John Collier (1967) for her dissertation on home-based culinary information collections. In 2006 she won the ALISE/Dialog Methodology Award for a paper outlining the approach. With Leslie Thomson she is the author of "Visual Approaches and Photography for the Study of Immediate Information Space" (Hartel \& Thomson, 2011) in the Journal of the American Society for Information Science and Technology. At the Faculty of Information she teaches a course on ethnography (Hartel, 2009) that includes a unit on visual methods.

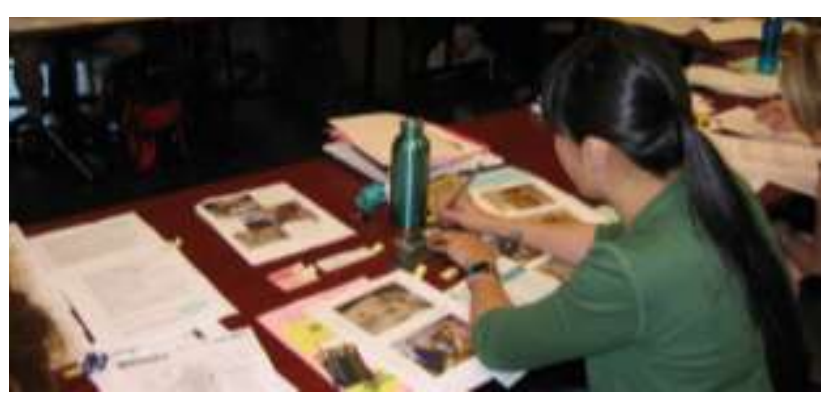

Figure 1. A student analyzes visual data in Dr. Hartel's course, The Information Experience in Context at the Faculty of Information, University of Toronto.

\section{Dr. Diane Sonnenwald, "The Information Horizon Interview"}

Dr. Sonnenwald is a widely respected scholar of information behavior and an expert on the concept of collaboration as it pertains to information work. In 1999 she generated an integrated framework of information behavior and also introduced the information horizon interview $(1999,2005)$, the sole visual technique designed to illustrate information behavior. Along with Barbara Wildemuth and Glynn Harmon, she won the 2001 ALISE/Dialog Methodology Award for this contribution (Sonnenwald, Wildemuth, \& Harmon, 2001). The information horizon approach has since been applied in many studies of information behavior and in a modified format is central to investigations of information practice (Savolainen, 2008). 


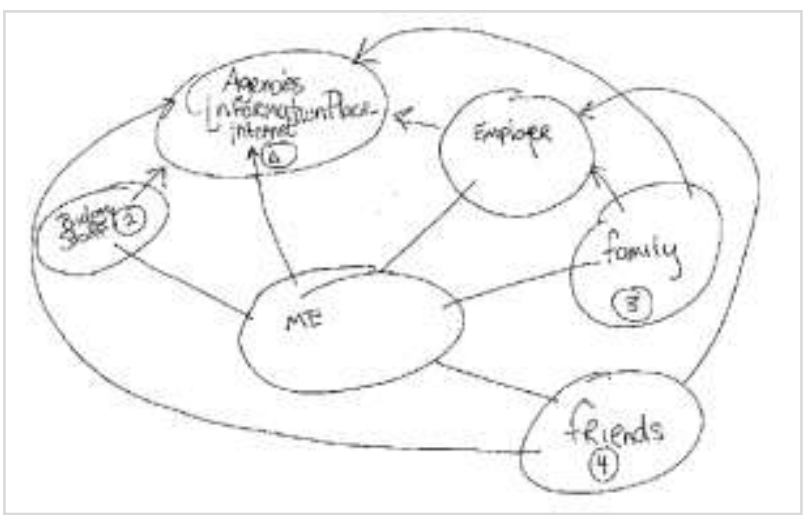

Figure 2. Exemplar information horizon drawings, illustrating the information resources in relation to a user, shown as "me" at center bottom (Sonnenwald, Wildemuth, \& Harmon, 2001).

\section{Dr. Anna Lundh, "Understanding and Illustrating Multimodal Information Activities"}

Dr. Anna Lundh is a researcher and teacher at the Swedish School of Library and Information Science at the University of Borås. In her dissertation Anna Lundh (2011) used visual ethnographical data collection methods in her studies of question-negotiations, information seeking, and information use in Swedish primary schools. The ethnographical data produced included video sequences, as well as other visual documents, and made detailed analyses of interactions and information sources possible. By including visual modes in data collection and analysis Lundh was able to operationalise and illustrate the theoretical stance that information activities are multimodal, social and material activities.



Figure 3. Sample cartoon used by Dr. Lundh (2010) to analyze reference transactions between youth and librarians.

Dr. Nancy Fried Foster, "Maps, Drawings, and Photographs from the University of Rochester Study"

Dr. Nancy Fried Foster is the Director of Anthropological Research for the University of Rochester's River Campus Libraries. She is editor, along with Susan Gibbons, of the breakthrough monograph Studying Students: The Undergraduate Research Project at the
University of Rochester, (Foster \& Gibbons, 2007), which featured several innovative visual methods. She is responsible for work-practice studies of faculty members, students and staff, and for ensuring that members of these groups participate in the design of technology, space and services. Dr. Foster holds a Diploma in Social Anthropology from the University of Oxford and a $\mathrm{PhD}$ in Applied Anthropology from Columbia University. She has extensive experience conducting anthropological research in the Amazon and Papua New Guinea as well as in higher education in the US and UK.
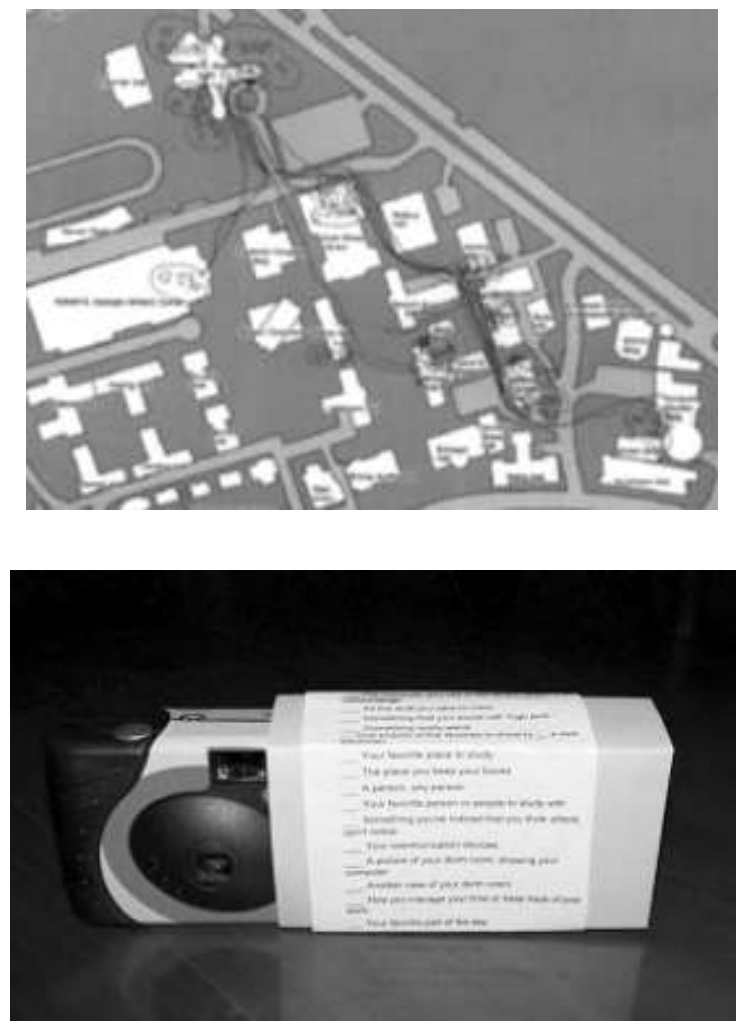

Figure 4. A mapping diary (top) produced by a student and the camera sent to research participants (bottom) to photograph their world. Both generated rich insights into student life and the role of the campus library at the University of Rochester.

\section{OUTCOMES}

Upon the conclusion of "State of the Art/Science: Visual Methods and Information Behavior Research" attendees will have gained: knowledge of the state of the art/science of visual methods in information behavior research; an appreciation for the richness the approach brings to the specialty; and a platform to take new visual research designs forward.

\section{REFERENCES}

Crabtree, A., \& Rodden, T. (2004). Domestic routines and design for the home. Computer Supported Collaborative Work, 13(2), 191-220. 
Foster, N. F. \& Gibbons, S. (2007). Studying students: The undergraduate research project at the University of Rochester. Chicago: Association of College and Research Libraries.

Hartel, J. (2003). The serious leisure frontier in library and information science: Hobby domains. Knowledge Organization, 30(3/4), 228-238.

Hartel, J. (2007). Information activities, resources, and spaces in the hobby of gourmet cooking. University of California, Los Angeles. ProQuest Dissertations and Theses, http://search.proquest.com/docview/304876976?accou ntid=14771

Hartel, J. (2009). Introducing the information experience in context. Faculty of Information Quarterly, 2(1). Retrieved from https://fiq.ischool.utoronto.ca/index.php/fiq/article/vie w/70/202.

Hartel, J. (2010). Hobby and leisure information and its user. In M. J. Bates, \& M. N. Maack (Eds.), Encyclopedia of Library and Information Science (3rd Edition). New York: Taylor and Francis.

Hartel, J., \& Thomson, L. (2011). Visual approaches and photography for the study of immediate information space. Journal of the American Society for Information Science and Technology, 62(11), 2214-2224.

Knowles, J. G., \& Cole, A. L. (Eds.). (2008). Handbook of the arts in qualitative research: Perspectives, methodologies, examples, and issues. Thousand Oaks, CA: Sage.

Lundh, A. (2011). Doing Research in Primary School: Information Activities in Project-Based Learning. Borås: Valfrid. Diss. [Available at http://bada.hb.se/handle/2320/8610]

Lundh, A. (2010). Studying information needs as questionnegotiations in an educational context: a methodological comment" Information Research, 15(4) paper colis722. [Available at http://InformationR.net/ir/15-4/colis722.html]
Lundh, A. \& Alexandersson, M. (2012). Collecting and Compiling: The Activity of seeking pictures in primary school. Journal of Documentation 68(2).

Prosser, J., \& Loxley, A. (2008). Introducing visual methods (National Centre for Research Methods Review Paper). Retrieved from http://eprints.ncrm.ac.uk/420/1/MethodsReviewPaperN CRM-010.pdf

Savolainen, R. (2008), Everyday information practices. A social phenomenological perspective. Lanham: Scarecrow Press.

Scull, C., Milewski, A., \& Millen, D. (1999). Envisioning the web: User expectations about the cyber-experience. Proceedings of ASIS Annual Meeting.

Sonnenwald, D. H. (1999). Evolving perspectives of human information behavior: Contexts, situations, social networks and information horizons. In T. D. Wilson \& D. K. Allen, eds., Exploring the contexts of information behavior: proceedings of the second international conference in information needs, seeking and use in different contexts. London: Taylor Graham, 176-190.

Sonnenwald, D.H. (2005). Information horizons In: K. Fisher, S. Erdelez, \& L. McKechnie (eds). Theories of Information Behavior: A Researcher's Guide. NY: Springer.

Sonnenwald, D. H., Wildemuth, B. M., \& Harmon, G. L. (2001). A research method using the concept of information horizons: An example from a study of lower socio-economic students' information seeking behavior. The New Review of Information Behavior Research, 2, 65-86.

Wagner, J. (2001). Does image-based fieldwork have more to gain from extending or rejecting scientific realism? Visual Sociology, 16(2), 7-21.

Weber, S. (2008). Using visual images in research. In J. G. Knowles \& A. L. Cole (Eds.), Handbook of the arts in qualitative research: Perspectives, methodologies, examples, and issues (pp. 41-54). London: Sage Press. 